\section{Community Mental Health Teams and primary health care}

SIR: Dr Strathdee's article (APT, September 1995, 1, 199-206) gives a detailed account of the ideal way in which a Community Mental Health Team might be deployed for the effective care of schizophrenics within the community. This is a highly intensive programme and was read with interest by myself and my colleagues when comparing the work load of the average psychiatrist for the elderly who may well have at least as many elderly patients with schizophrenia in the community. The numbers will include those schizophrenics who have grown old in the course of their illness, but also those with schizophrenia of late life.

One of the things that concerns me is that she talks about the need for shared care and primary care liaison, and in box 4 of the article proposes a range of initiatives to improve joint working between primary health care teams and the CMHT. While what she lists seems very desirable, it does not seem to take account of the difficulties that many of us experience in getting GPs to attend Care Programme meetings, and subsequently to agree out patient or community nurse interventions that may be required over a prolonged period of time for such patients. It certainly seems that fundholding GP practices who put mental health as a low priority in their budgeting may not make the most efficient kind of community health team management of schizophrenics very easy.

I hope that efforts like my own team's approaches to give talks to GP practices, about how we operate and the kind of service that we feel is appropriate to provide, will help to improve this situation, but it certainly is extremely time consuming and has to be squeezed into a very heavy clinical case-load.

D. R. D. WALLACE

Leeds Community \& Mental Health Services

High Royds Hospital

Menston, Ilkley

West Yorkshire LS29 6AQ

\section{Critical appreciation}

SIR: In response to your plea for comments from consultants regarding $A P T$, I would like to offer my support for the way the programme has been devised. I find the articles, in the main, most helpful and informative and are just what are needed, i.e. an overview of the current status on any particular topic. One slight criticism is that some of the articles are a little bit too long, given that most consultants have very little time for reading. The content has influenced my clinical practice already and I welcome topics that are of current interest such as the Care Programme Approach which we have been wrestling with. I am involved in developing a computerised system for old age psychiatry and trying to combine it with ordinary clinical practice. This particular article is, therefore, most welcome.

I endorse your belief that $A P T$ is useful for subconsultant doctors and I have recommended it as essential reading for my staff grade. Some articles critically appraising some topics and expressing different points of view would also be welcome, as sometimes appear in the British Journal of Psychiatry. If anything, I would like more articles on Government policy and how it works in practice. Comparisons with other countries would be extremely useful. You might also give some consideration to articles which might be more managerial in nature. Being an effective manager as well as a clinician is now an increasingly important role for any consultant. I, personally, have spent quite a bit of study leave on improving my managerial skills, which not only assist in that area of work but also with the clinical side, an example being effective time management.

N. Pearson

Dorset HealthCare NHS Trust
Oakley House
15 Oakley Lane
Canford Magna
Nr Wimborne
BH21 1SF

